\title{
Efficacy of ingenol mebutate gel for actinic keratosis in patients treated by thiazide diuretics
}

\author{
Elena Campione' \\ Monia Di Prete' \\ Laura Diluvio' \\ Luca Bianchi' \\ Augusto Orlandi ${ }^{2}$ \\ 'Department of Dermatology, \\ ${ }^{2}$ Department of Pathology, University \\ of Rome Tor Vergata, Rome, Italy
}

Correspondence: Elena Campione

Department of Dermatology, University

of Rome Tor, Viale Oxford, 8I, 00I33

Rome, Italy

Tel +39620900252

Fax +39620902742

Email campioneelena@hotmail.com
This article was published in the following Dove Press journal:

Clinical, Cosmetic and Investigational Dermatology

7 November 2016

Number of times this article has been viewed

\begin{abstract}
Actinic keratosis (AK) is considered as superficial squamous cell carcinoma. Chronic sun exposure plays a central role in its pathogenesis. In particular, ultraviolet $\mathrm{B}$ radiation causes direct damage to the DNA, producing pyrimidine dimers that suppress the protective role of $\mathrm{p} 53$. Other risk factors include advanced age, male sex, and fair skin type. Even some drugs used for treating blood hypertension, such as thiazide diuretics, can increase the risk of developing AK. Their photosensitizing action seems to be connected with reactive oxygen species production. We report our experience with ten patients affected by multiple AK, in therapy with thiazide diuretics, treated by ingenol mebutate gel. AK was clinically and dermoscopically evaluated at baseline and after 30 days from the beginning of the treatment. Moreover, patients were screened for vitamin $\mathrm{D}_{3}$ values and reported a general hypovitaminosis status. To our knowledge, we report for the first time the efficacy of ingenol mebutate gel in this group of patients, particularly at risk of developing AK

Keywords: anticancer agents, antitumor activity, cancer cells, skin precancerous lesion
\end{abstract}

\section{Introduction}

Actinic keratosis (AK) is an intradermal proliferation of atypical keratinocytes. AKs are considered as superficial squamous cell carcinoma (SCC), because they are fundamentally indistinguishable in terms of cytology and are similar for molecular biology. ${ }^{1}$ Clinically, AKs mostly present as squamous or hyperkeratotic papules on an erythematous background, but they can also present as pigmented, lichenoid, or cutaneous horn. A sandpaper-like texture is revealed by palpation and surrounding skin generally shows the chronic sun damage signs. ${ }^{2}$ Based on their features, people can have single or multiple AKs: patients with single lesions usually are young or old people with fair skin type. Immunosuppressed people who spend a lot of time outdoors or in photosensitization treatment have generally multiple lesions. ${ }^{3,4} \mathrm{~A}$ central role in the pathogenesis of the lesions is played by the chronic ultraviolet (UV) radiation exposure. In particular, UVB can cause direct DNA damage, producing pyrimidine dimers. It can lead to suppression of $\mathrm{p} 53$ function which seems to be the most important pathway in the development of both AKs and SCCs, with the consequence of clonal expansion of keratinocytes. ${ }^{5}$ On the other hand, UVA, absorbed by skin chromophores, can generate reactive oxygen species that are mutagenic for DNA ${ }^{6,7}$ Human papilloma virus seems to play a marginal role and acts as a cofactor of UV radiation-induced DNA alterations in the development of AKs. ${ }^{8}$ The main risk factors include advanced age, male sex, cumulative sun exposure, and fair skin type. Organ transplant recipients, as well as people treated with chemotherapy, antibiot- 
ics, nonsteroidal anti-inflammatory drugs, and diuretics have higher risk than the general population for developing AKs. ${ }^{9}$ Diuretics are a class of antihypertensive drugs and thiazide diuretics, in particular, are significantly associated with increased risk of SCC. Their photosensitizing action may be due to conversion to electrophiles or production of reactive oxygen species. ${ }^{3}$ There are two different and effective treatments for AKs: lesion-directed and field-directed therapies. The lesion-directed treatments aim to destroy or remove atypical keratinocytes, whereas the field-directed therapies not only act against the lesion, but also against areas with subclinical atypical keratinocytes within a field of chronic sun exposed and damaged skin, the so-called field of cancerization. ${ }^{10-12}$ Among the latter novel therapies, ingenol mebutate gel, an extract from the plant Euphorbia peplus, induces swelling of mitochondria of dysplastic keratinocytes and cell death by primary necrosis. Its topical application generates a neutrophil infiltration, due to protein-kinase $\mathrm{C}$ activation, causing effective wound healing. ${ }^{13-15}$ Phase 3 studies have revealed the efficacy of ingenol mebutate gel at concentrations of $0.015 \%$ (for the face/scalp) and $0.05 \%$ (for the trunk/extremities) in clearing AKs, with remission over 12 months. ${ }^{16}$ We report cases of ten patients affected by multiple AKs, undergoing therapy with thiazide diuretics for hypertension, treated using ingenol mebutate gel in different concentrations depending on the region to treat.

\section{Material and methods}

Patients with AKs received ingenol mebutate gel in different concentrations on the basis of localization of their lesions, $0.015 \%$ for face and scalp and $0.05 \%$ for trunk and extremities, for 3 and 2 consecutive days, respectively. Eligibility criteria included an age of at least 18 years, presence of one or more AKs, and current treatment with thiazide diuretics for hypertension. The main exclusion criterion was other concomitant therapies for AKs. Females included in the study were not pregnant or breast-feeding. Ten patients (five females and five males), mean age 64.2 years (from 55 to 75 years), in good blood pressure control, were involved in the study (Table 1). No other dermatological disorders were referred. All patients signed a written consent before starting the therapy, and the study was conducted following the ethical guidelines of the Helsinki Declaration. As ingenol mebutate is approved for the treatment of actinic keratosis there was no formal ethical review board approval sought. Enrolled patients were affected by multiple AKs (a total of 24 lesions from 3.2 to $15 \mathrm{~mm}$ diameter) localized all over the body surface. All patients were educated to self-apply the medical device on the target lesion and perilesional field of cancerization $\left(25 \mathrm{~cm}^{2}\right)$. Short-distance lesions were treated at the same time if they were in a $25 \mathrm{~cm}^{2}$ diameter area, otherwise in two different times. Patients were also informed of the normal important skin reaction that would have been expected in the days following the topical application and they were asked to communicate any side effects that lay outside this one (eg, infections, allergy, and swelling). AKs were clinically and dermoscopically evaluated at baseline and at 1 month from the beginning of the treatment. From a clinical point of view, AKs were recognized by their typical sandpaper-like texture revealed by palpation. Surrounding skin generally showed chronic sun damage signs. Dermoscopy features defining AKs were erythematous pseudonetwork for facial lesions and erythematous background for the ones localized elsewhere, and white-yellowish surface scales and atrophic hypopigmented areas for everywhere placed lesions. The end-point was the complete, clinical, and dermoscopic clearance of AKs after the treatment. Afterwards, the patients were followed for approximately a year with no evidence of recurrence of the disease.

Table I General information about patients involved in the study

\begin{tabular}{lllll}
\hline Sex & Age (years) & Localization & Vitamin $\mathbf{D}_{\mathbf{3}}$ (ng/mL) & Therapy \\
\hline M & 58 & Back, left forearm & 12.40 & HCT (5 years) \\
M & 69 & Back (2 ${ }^{\#}$, right forearm, right hand & 10.20 & HCT (8 years) \\
F & 75 & Left cheek*, forehead & 11.50 & HCT (I0 years) \\
M & 56 & Nose, chin & 22.00 & HCT (5 years) \\
F & 59 & Nose, left leg & 13.10 & HCT (4 years) \\
M & 67 & Left forearm, left hand & 12.00 & HCT (7 years) \\
M & 68 & Back, right arm & 11.80 & HCT (I0 years) \\
F & 55 & Right cheek, left forearm & 20.50 & HCT (4 years) \\
F & 60 & Nose*, neckline $\left(2^{\#}\right)$ & 17.60 & HCT (8 years) \\
F & 75 & Nose, neckline, forehead & 14.40 & HCT (8 years) \\
\hline
\end{tabular}

Note: *Lesions in figures. "The number of the lesions localized in that place.

Abbreviations: $\mathrm{F}$, female; HCT, hydrochlorothiazide; M, male. 


\section{Results}

We enrolled ten patients (five females and five males; mean age 64.2 years) affected by multiple AKs (24 total lesions, from 3.2 to $15 \mathrm{~mm}$ diameter, localized on face, scalp, trunk, and upper and lower extremities) that consecutively referred to the Dermatological Unit of our Hospital for a general skin examination (Table 1). They were on treatment with thiazide diuretics for their hypertension. The mean duration of the treatment with hydrochlorothiazide was 6.9 years (from 4 to 10 years). AKs were clinically and dermoscopically evaluated (their images were archived in our database) at baseline and after 1 month. It was prescribed ingenol mebutate gel at concentrations of $0.015 \%$ for lesions of face and scalp and $0.05 \%$ for those of trunk and extremities. In the first case, the drug was topically applied for three consecutive nights and in the latter for two consecutive nights. None of them reported particular side effect (eg, infections of the treated areas and allergy). Everyone had an important erythematous reaction at the site of application with vesicles and crusts that began within the first day of application and peaked during the following week, and totally resolved in $<2$ months. Despite the important sun damage that could result in lower treatment effectiveness, these patients' response was excellent, leaving the underlying skin completely clear from lesions after only one cycle of therapy (Figures 1-3). Afterwards, patients were followed for approximately a year with no evidence of recurrence of the disease. Before the beginning of the treatment, all patients were screened for vitamin $\mathrm{D}_{3}$ values and reported a general hypovitaminosis status (mean value $14.55 \mathrm{ng} / \mathrm{mL}$, normal range $30-80 \mathrm{ng} / \mathrm{mL}$ ).

\section{Discussion}

We analyzed a cohort of ten patients and found a general hypovitaminosis D status (mean value $14.55 \mathrm{ng} / \mathrm{mL}$, values from 10.20 to $22.00 \mathrm{ng} / \mathrm{mL}$ ). Many investigations have indicated that vitamin $\mathrm{D}_{3}$ action reduces risk of nonmelanoma skin cancers, maybe modulating p53 response to DNA damage in SCC. ${ }^{17,18}$ The association between plasma 25-hydroxy-vitamin D (25(OH)D) levels and the incident risk of SCC has been recognized, and could be, together
A

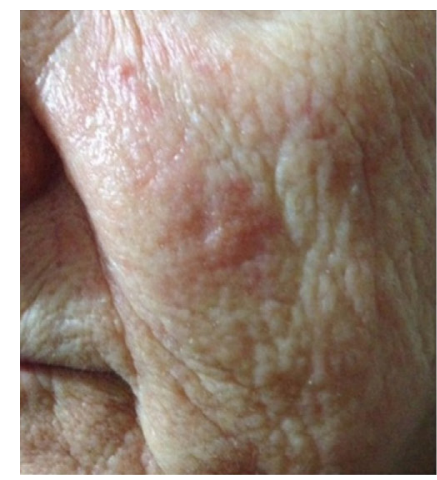

B

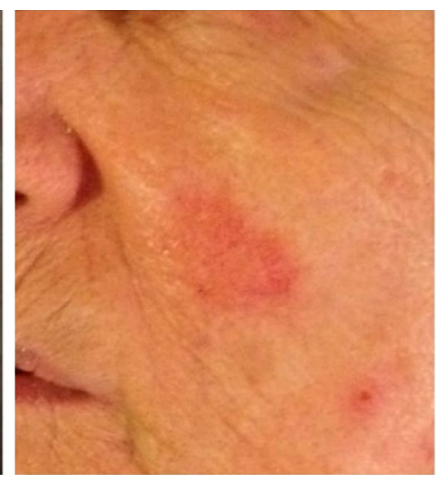

C

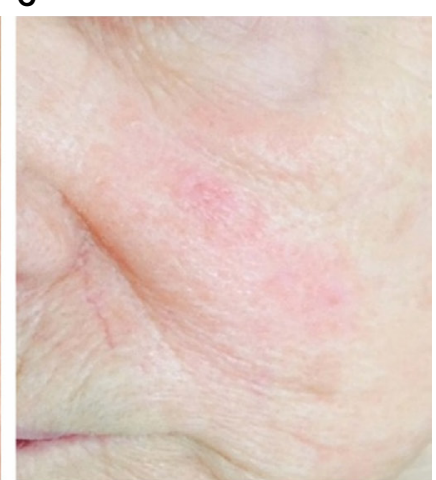

Figure I A 75-year-old woman affected by actinic keratosis of the left cheek.

Notes: (A) Diameter before therapy approximately $1 \mathrm{~mm}$. (B) Reaction after 3 consecutive days application of ingenol mebutate gel $0.015 \%$. (C) Complete clearance after I month from the end of treatment.

A

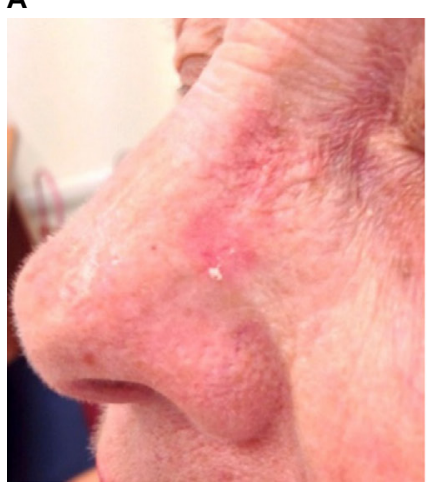

B

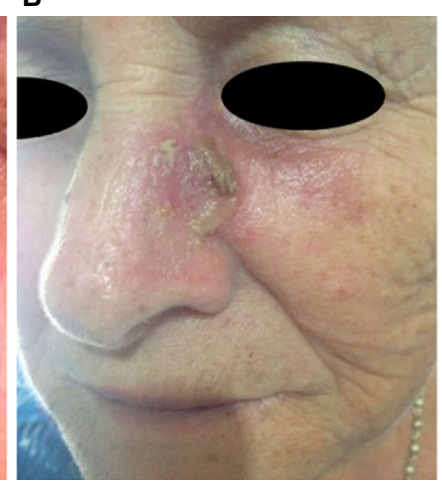

C

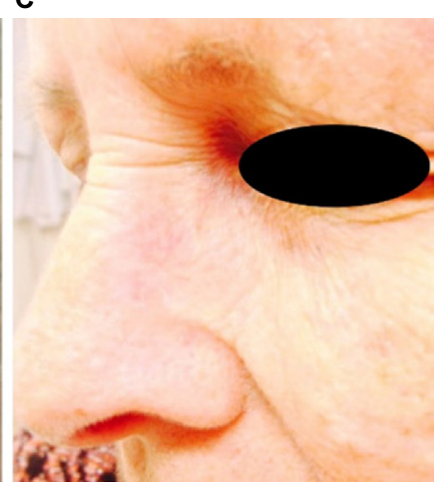

Figure 2 A 59-year-old woman affected by actinic keratosis of the left side of the nose.

Notes: (A) Diameter before therapy approximately $6 \mathrm{~mm}$. (B) Important inflammatory reaction after 3 consecutive days application of ingenol mebutate gel $0.015 \%$. (C) Complete clearance after I month from the end of treatment. 


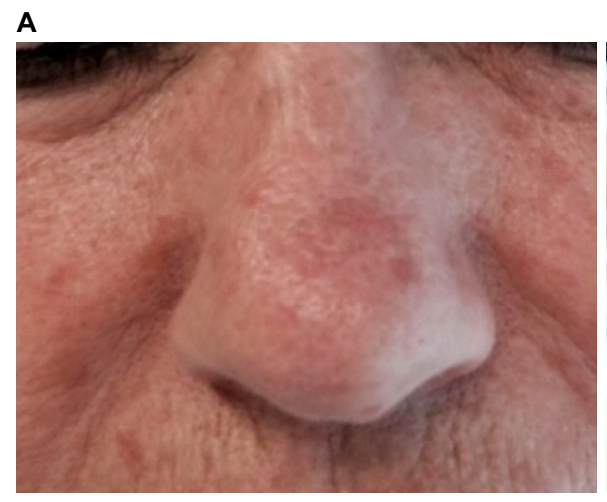

B

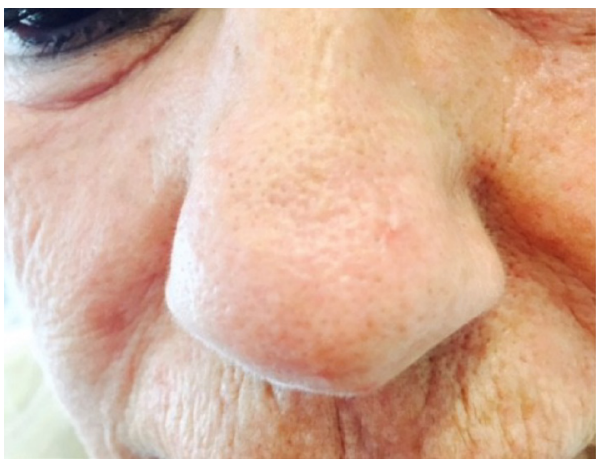

Figure 3 A 60-year-old woman affected by actinic keratosis of the nose.

Notes: (A) Diameter before therapy approximately $13 \mathrm{~mm}$. (B) Complete clearance after I month from the end of treatment with ingenol mebutate gel $0.015 \%$ applied for 3 consecutive days.

with photoprotection, one of the parameters based on which patients having major risk factors for the development of SCC can be treated. Patients treated with thiazide diuretics show, in our experience, greater photo- and chrono-aging (xerosis, thin skin, fine wrinkles, and loss of elasticity) compared with the general population based on clinical and dermoscopic evaluations. As the epidermis is the major source of vitamin $\mathrm{D}_{3}$ and aged skin has less capacity to synthesize this component, it is conceivable that the hypovitaminosis status, typical of this group of patients, is ascribable to their treatment with thiazide diuretics. Therefore, the accelerated skin aging found in this group of patients might be both the cause and effect of the severe vitamin D deficiency. A population-based case-control study in 2008 in Denmark by Jensen showed association between diuretics usage, especially hydrochlorothiazide, and SCC development. Moreover, the study found an increase in the risk of tumor with an increase in the dosage of drug. The pathogenic mechanism is considered to be an interaction with UV radiation as demonstrated for another diuretic molecule, amiloride. ${ }^{19}$ Recently, a further case-control study was published and found an increased, yet imprecise, risk of SCC among Americans on treatment with diuretics. ${ }^{20}$ Thiazide diuretics are used to lower hypertension and reduce the risk of cardiovascular disease. They act on the luminal membrane of the distal convoluted tubule of the ascending loop of Henle. After being secreted into the tubular lumen, they inhibit the sodium chloride cotransporter and cause natriuresis. Moreover, they increase the secretion of potassium and hydrogen ions, increase the expression of sodiumcalcium exchange channel, and promote the reabsorption of calcium..$^{21,22}$ The diuresis and blood volume reduction are the early causes of pressure decreasing. The exact mechanism on long-term period response is not yet known. The most common side effect described is electrolyte disturbance, in particular hypokalemia, followed by hypochloremic alkalosis, hyponatremia, and hypercalcemia. ${ }^{23}$ Ingenol mebutate has demonstrated its extraordinary effectiveness in a group of patients particularly at risk of nonmelanoma skin cancers. The induction of necrosis in dysplastic keratinocytes is a winning strategy in these skin tumors. ${ }^{13-15}$ On one hand, ingenol mebutate permits to treat AKs and avoids their evolution into SCC, and on the other hand, it also makes it possible to heal the cancerization field. Nowadays, it is understood that the field of cancerization has the same importance as lesions, as it represents a large area of chronic sun damage, whence new precancerous and tumor lesions can develop in the future. ${ }^{24}$

\section{Conclusion}

Our clinical observation is useful for patients who have to perform this specific diuretic photosensitization therapy to suggest strategies that try to prevent nonmelanoma skin cancer development. Assuring good plasma 25(OH)D levels and investigating other factors that may influence its action (receptor status, binding protein levels, synthesis and catabolism mechanisms) could be the first step in this direction. Further studies are needed to determine the real photosensitizing mechanism of thiazide diuretics. To the best of our knowledge, we report for the first time the extraordinary efficacy of ingenol mebutate gel in this peculiar group of patients particularly at risk of developing nonmelanoma skin cancers.

\section{Acknowledgments}

In memory of our Professor Sergio Chimenti, recently passed away, who was a guide and a mentor for us.

All the patients gave their consent to use their photos for the publication. 


\section{Author contributions}

All authors contributed toward data analysis, drafting and critically revising the paper and agree to be accountable for all aspects of the work.

\section{Disclosure}

The authors report no conflicts of interest in this work.

\section{References}

1. Ackerman AB, Mones JM. Solar (actinic) keratosis is squamous cell carcinoma. Br J Dermatol. 2006;155(1):9-22.

2. Schmitt JV, Miot HA. Actinic keratosis: a clinical and epidemiological revision. An Bras Dermatol. 2012;87(3):425-434.

3. de Vries E, Trakatelli M, Kalabalikis D, et al. Known and potential new risk factors for skin cancer in European populations: a multicentre case-control study. Br J Dermatol. 2012;167 Suppl 2:1-13.

4. Gould JW, Mercurio MG, Elmets CA. Cutaneous photosensitivity diseases induced by exogenous agents. J Am Acad Dermatol.1995;33(4): 551-573

5. Nomura T, Nakajima H, Hongyo T, et al. Induction of cancer, actinic keratosis, and specific p53 mutations by UVB light in human skin maintained in severe combined immunodeficient mice. Cancer Res. 1997;57(11):2081-2084.

6. Garland CF, Garland FC, Gorham ED. Epidemiologic evidence for different roles of ultraviolet $\mathrm{A}$ and $\mathrm{B}$ radiation in melanoma mortality rates. Ann Epidemiol. 2003;13(6):395-404.

7. Rinnerthaler M, Bischof J, Streubel MK, Trost A, Richter K. Oxidative stress in aging human skin. Biomolecules. 2015;5(2):545-589.

8. Queille S, Luron L, Spatz A, et al. Analysis of skin cancer risk factors in immunosuppressed renal transplant patients shows high levels of UVspecific tandem CC to TT mutations of the p53 gene. Carcinogenesis. 2007;28(3):724-731.

9. Tessari G, Girolomoni G. Nonmelanoma skin cancer in solid organ transplant recipients: update on epidemiology, risk factors, and management. Dermatol Surg. 2012;38(10):1622-1630.

10. Babino G, Diluvio L, Bianchi L, et al. Long-term use of a new topical formulation containing piroxicam $0.8 \%$ and sunscreen: efficacy and tolerability on actinic keratosis. A proof of concept study. Curr Med Res Opin. 2016;32(8):1345-1349.
11. Campione E, Paternò EJ, Candi E, et al. The relevance of piroxicam for the prevention and treatment of nonmelanoma skin cancer and its precursors. Drug Des Devel Ther. 2015;9:5843-5850.

12. Bianchi L, Campione E, Marulli GC, Costanzo A, Chimenti S. Actinic keratosis treated with an immune response modifier: a case report of six patients. Clin Exp Dermatol. 2003;28(Suppl 1):39-41.

13. Ogbourne SM, Suhrbier A, Jones B, et al. Antitumor activity of 3-ingenyl angelate: plasma membrane and mitochondrial disruption and necrotic cell death. Cancer Res. 2004;64(8):2833-2839.

14. Cozzi SJ, Le TT, Ogbourne SM, James C, Suhrbier A. Effective treatment of squamous cell carcinomas with ingenol mebutate gel in immunologically intact SKH1 mice. Arch Dermatol Res. 2013;305(1):79-83.

15. Cozzi SJ, Ogbourne SM, James C, et al. Ingenol mebutate field-direct treatment of UVB-damaged skin reduces lesion formation and removes mutant p53 patches. J Invest Dermatol. 2012;132(4):1263-1271.

16. Lebwohl M, Shumack S, Stein Gold L, et al. Long-term follow-up study of ingenol mebutate gel for the treatment of actinic keratoses. JAMA Dermatol. 2013;149:666-670.

17. Reichrath J, Reichrath S. The relevance of the vitamin D endocrine system (VDES) for tumorigenesis, prevention, and treatment of nonmelanoma skin cancer (NMSC): present concepts and future perspectives. Dermatoendocrinol. 2013;5(1):38-50.

18. Caini S, Boniol M, Tosti G, et al. Vitamin D and melanoma and nonmelanoma skin cancer risk and prognosis: a comprehensive review and meta-analysis. Eur J Cancer. 2014;50(15):2649-2658.

19. Jensen AØ, Thomsen HF, Engebjerg MC, Olesen AB, Sørensen HT, Karagas MR. Use of photosensitising diuretics and risk of skin cancer: a population-based case-control study. Br J Cancer. 2008;99: $1522-1528$.

20. Robinson SN, Zens MS, Perry AE, Spencer SK, Duell EJ, Karagas MR. Photosensitizing agents and the risk of non-melanoma skin cancer: a population-based case-control study. J Invest Dermatol. 2013;133(8): 1950-1955.

21. Eladari D, Chambrey R. Identification of a novel target of thiazide diuretics. J Nephrol. 2011;24(4):391-394.

22. Cooney D, Milfred-LaForest S, Rahman M. Diuretics for hypertension: hydrochlorothiazide or chlorthalidone? Cleve Clin J Med. 2015; 82(8):527-533.

23. Palmer BF. Metabolic complications associated with use of diuretics. Semin Nephrol. 2011;31(6):542-552.

24. Costa C, Scalvenzi M, Ayala F, Fabbrocini G, Monfrecola G. How to treat actinic keratosis? an update. J Dermatol Case Rep. 2015;9(2): 29-35.
Clinical, Cosmetic and Investigational Dermatology

\section{Publish your work in this journal}

Clinical, Cosmetic and Investigational Dermatology is an international, peer-reviewed, open access, online journal that focuses on the latest clinical and experimental research in all aspects of skin disease and cosmetic interventions. This journal is included on PubMed. The manuscript management system is completely online

\section{Dovepress}

and includes a very quick and fair peer-review system, which is all easy to use. Visit http://www.dovepress.com/testimonials.php to read real quotes from published authors 